\title{
A Study To Locate The Difference Between Active And Passive Recovery After Strenuous Workout.
}

\author{
*Dr. Saikot Chatterjee. **Miss, Maitreyee Maity *** \\ Dr. Samir Ranjan Adhikary. \\ * Asst. Prof. Department of Physical Education, University of Kalyani. Nadia, West Bengal, India. \\ ** Student M.P.Ed. $2^{\text {nd }}$ Sem. University of Kalyani, Nadia, West Bengal, India. \\ *** Asst. Prof. S.S. College of Education Simurali, Nadia, West Bengal, India.
}

\begin{abstract}
Exercise recovery involves a number of Post-exercise Steps that are essential for any exercise regime, regardless of fitness level, the type of physical activity or the exercise intensity. Exercise recovery does not take long or require much effort, but it is often neglected. The exercise recovery is mainly of two types one is Active Recovery and the other is passive Recovery. Active Recovery is the term used for cooling down (with slow jogging, stretching etc. ) after a high intensive work out and Passive Recovery is Stopping dead, doing nothing again until he head out on his next run a couple of days later. The results of a study suggest that an active recovery of 3 minutes between High intensity, short duration exercise bouts significantly increase peak power and average power compared to a passive recovery, irrespective of changes in blood lactate levels. Several research studies have been conducted in this specific area in the international level but the effort is supposed to be weaker with respect to Indian Sport Scientists. Feeling the importance of recovery in the sport field and considering its application in a wider range or rather as an effort to make it much more acceptable to the sport society the investigator under the guidance of her supervisor envisaged to conduct the study entitled "A study to locate the difference between active and passive recovery after strenuous workout." The subjects for the present study were 20 male trained athletes from Howrah and Purba Medinipur districts of West Bengal who were selected randomly from a coaching camp. In the present study, the investigator has considered the following things such as their - Age, sex, Height of the subject, Resting Heart Rate, Post Exercise Heart Rate, After Active Recovery Heart Rate, After Passive Recovery Heart Rate. The scholar made the athletes to run $600 \mathrm{mts}$. and recorded their Heart Rate just after completion of the workout and also recorded their HR after one minute of complete rest the same procedure was repeated but in between the athletes were directed to perform active recovery i.e. slow jogging. From data analysis it appears that the Active recovery is superior in comparison to the Passive recovery because the recovery range is greater. Thus the scholar arrived at the explicit conclusion that active recovery is better than passive recovery between exercise bouts or after strenuous workout.
\end{abstract}

Key Words: Active recovery, Passive Recovery, Strenuous workout.

\section{Introduction}

Exercise is an essential part of maintaining a happy and healthy life, but it is not without risk of injury. To minimize these risks and perform optimally the next time doing exercise, the athlete must allow his body to recover. Exercise recovery involves a number of Post-exercise Steps that are essential for any exercise regime, regardless of fitness level, the type of physical activity or the exercise intensity. Exercise recovery does not take long or require much effort, but it is often neglected.

The exercise recovery is mainly two types one is Active Recovery and the other is passive Recovery. Active Recovery is the term used for cooling down after a short duration high intensive work out and Passive Recovery is Stopping dead, Stretching and then doing nothing again until he head out on his next run a couple of days later. The results of a study suggest that an active recovery of 3 minutes between High intensity, short duration exercise bouts significantly increase peak power and average power compared to a passive recovery, irrespective of changes in blood lactate levels. Studies now show that the Stopping dead and Stretching and going home away not be the best way to aid recovery after a workout. It has been proven that slowing pace down at the end of run, doing Knee lift or Kick. For years we've been told to take one to two days a week of from exercising in order to let bodies recover. While it is important to always listen to his body. Exercise known as "Active Recovery" may actually help his body recover quicker soreness compared to "Passive Recover".

Passive Recovery is defined as allowing his body to completely rest from exercise. While Active Recovery is any sort of low intensity exercise that makes feel better after exercising compared to before you started. It's important to note that Active Recovery is unique to each individual's fitness level. For example for Marathon Runners, this might mean jogging on an off day. The advantage of active versus passive Recovery on subsequent performances in short duration, high intensity exercise has been well documented (Ainsworth 
etal.1993; Stanley et al, 1988). Furthermore it has been suggested that low intensity work lasting 20-40 minutes is appropriate to prevent decreased power output on repeated bouts of short duration, high intensity exercise (Bangsbo et al, 1994). High intensity exercise results in increased levels of both intra muscular and circulating levels of lactate. The results of a study suggest that an active recovery of 3 minutes between High intensity, short duration exercise bouts significantly increase peak power and average power compared to a passive recovery, irrespective of changes in blood lactate levels. In the sport field recovery or recuperating in between exercise bouts or performances is awfully crucial. There is quite a many situation where the athlete has to perform within short or little longer intervals. Here comes the importance of recovery, hence the author being an athlete premeditated to design the aforesaid study to bring some practical basis having utmost application for any athlete.

Feeling the importance of recovery in the sport field and considering its application in a wider range or rather as an effort to make it much more acceptable to the sport society the investigator under the guidance of her supervisor envisaged to conduct the study entitled "A study to locate the difference between active and passive recovery after strenuous workout." Purposes of the study were to assess the recovery heart rate of athletes with active relaxation, to assess the recovery heart rate of athletes with passive relaxation and to compare the difference between active and passive recovery after a short duration high intensive exercise. The subjects for the present study were 20 male trained athletes from Howrah and Purba Medinipur districts, of West Bengal who were selected randomly from a coaching camp In the present study, the investigator has considered the following things such as the Age, sex, Height and weight of the subjects, their Resting Heart Rate, Post Exercise Heart Rate, After Active Recovery Heart Rate and After Passive Exercise Heart Rate.

The scholar made the athletes to run $600 \mathrm{mts}$. and recorded their Heart Rate just after completion of the workout and also recorded their HR after one minute of complete rest the same procedure was repeated but in between the athletes were directed to perform active recovery i.e. slow jogging. The data were collected according to the following means and methods for recording the Resting heart rate the subjects were made to assemble in a hall early in the morning and the HR were estimated with the help of a pulse monitor after 30 minute complete rest. A 30 seconds pulse count was recorded in each time with the help of a stop watch. The mean reading of 2-3 trials was recorded as resting heart rate of the subject. Post exercise heart rate was estimated immediately after the completion of $600 \mathrm{mt}$ run, after completion of $600 \mathrm{mt}$ run the subjects were directed to go for $1 \mathrm{~min}$. slow jogging after one minute the H.R was immediately recorded which gave the active recovery Heart Rate, after completion of $600 \mathrm{mt}$ run the subjects were directed to take complete rest for 1 minute then the passive Recovery H.R was measured and recorded immediately.

The descriptive statics is as follows:

Table.1. Mean age, height and weight of the subjects

\begin{tabular}{|l|r|r|r|r|r|}
\hline & \multicolumn{1}{|c|}{$\mathrm{N}$} & \multicolumn{1}{|c|}{ Minimum } & \multicolumn{1}{c|}{ Maximum } & \multicolumn{1}{c|}{ Mean } & \multicolumn{1}{c|}{ Std. Deviation } \\
\hline Height cms. & 20 & 150.00 & 174.00 & 163.3000 & 7.23369 \\
Weight kg. & 20 & 42.00 & 65.00 & 51.9000 & 6.65622 \\
Age yrs. & 20 & 15.00 & 22.00 & 18.0000 & 1.83533 \\
Valid N (listwise) & 20 & & & & \\
\hline
\end{tabular}

According to table 1.the mean height, weight and age, of the subjects are 174.00, 65, and 22 respectively and their S.D. is $7.23,6.65$ and 1.83 .

Table.2. Paired sample statistics between active and passive recovery.

\begin{tabular}{|l|c|r|r|r|}
\hline & Mean & N & Std. Deviation & $\begin{array}{c}\text { Std. Error } \\
\text { Mean }\end{array}$ \\
\hline ACTIVE.RE.HR & 114.65 & 20 & 13.597 & 3.040 \\
\hline PASSIVE RE.HR & 119.70 & 20 & 16.693 & 3.733 \\
\hline
\end{tabular}

Table 2 shows the means of active recovery heart rate and passive recovery heart rate after exercise which are ARHR 114.65 and PRHR 119.70. it is clear from the data that heart rate recovery is greater in case of active recovery further paired sample $t$ test was computed to locate the degree of difference between the means.

Table.3. Paired sample $t$ test between active and passive recovery.

\begin{tabular}{|c|c|c|c|c|c|c|c|c|}
\hline & \multicolumn{5}{|c|}{ Paired Differences } & \multirow[t]{3}{*}{$\mathrm{T}$} & \multirow[t]{3}{*}{$\mathrm{df}$} & \multirow[t]{2}{*}{ Sig. (2-tailed) } \\
\hline & \multirow[t]{2}{*}{ Mean } & \multirow[t]{2}{*}{$\begin{array}{c}\text { Std. } \\
\text { Deviati } \\
\text { on }\end{array}$} & \multirow[t]{2}{*}{$\begin{array}{l}\text { Std. } \\
\text { Error } \\
\text { Mean } \\
\end{array}$} & \multicolumn{2}{|c|}{$\begin{array}{l}95 \% \text { Confidence } \\
\text { Interval of the } \\
\text { Difference }\end{array}$} & & & \\
\hline & & & & Lower & Upper & & & \\
\hline $\begin{array}{l}\text { ACTIVE.RE.HR - PASSIVE } \\
\text { RE.HR }\end{array}$ & -5.050 & 9.327 & 2.086 & -9.415 & -0.685 & -2.421 & 19 & 0.026 \\
\hline
\end{tabular}

From table 3 it is clear that the difference between the means is significant at 0.05 levels. Hence it can be deduced that active recovery is better than passive recovery between exercise bouts or after strenuous workout. 


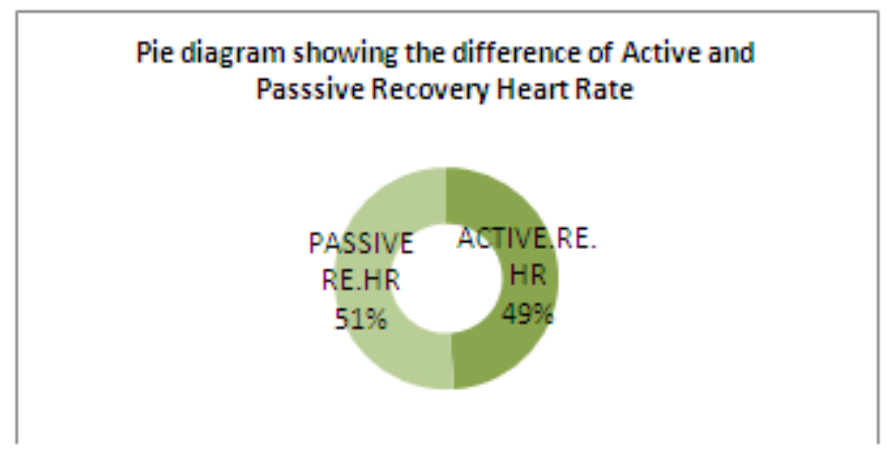

From the above pie diagram also it is clear that the Active Recovery is lower than Passive Recovery Heart rate hence it is revealed that active recovery facilitate or aid the recovery process after work out while passive recovery hinders the same.

Thus from the above discussion and data analysis it is obvious that the Active recovery is superior in comparison to the Passive recovery because the recovery range is greater. The advantage of active versus passive Recovery on subsequent performances in short duration, high intensity exercise has been well documented (Ainsworth etal.1993; Stanley et al, 1988). Furthermore it has been suggested that low intensity work lasting 20-40 minutes is appropriate to prevent decreased power out put on repeated bouts of short duration, high intensity exercise (Bangsbo et al, 1994). High intensity exercise results in increased levels of both intra muscular and circulating levels of lactate. The findings of the present definitely have close proximity with the findings of other renowned scholars. Thus the scholar arrived at the explicit conclusion that active recovery is better than passive recovery between exercise bouts or after strenuous workout.

\section{References}

[1]. Emerson F, Alexandre V. N. Josué M. M. Fabrício B. D. V., J. of Physio, Antro, 2007, vol. 26. No. 2, 59-67.

[2]. Franchini E, Del Vecchio FB, Matsushigue KA, Artioli GG. Sports Med. 2011 Feb 1;41 (2):147-66.

[3]. Franchini E, de Moraes Bertuzzi RC, Takito MY, Kiss MA. Eur J Appl Physiol. 2009 Nov;107(4):377-83

[4]. Ainsworth, B.E., Serfass, R.C., and leon A.S. Canadian Journal of Applied Physiology, 1993 18, 19-30.

[5]. Stanley, W.c., Winseski, J.A., E.W. Gertz, E.W., Neese, R.A. and Brooks, G.a. Metabolism, 1983, 37, 850-858.

[6]. Bangsbo, J., Graham, T., Johansen, L., and Saltin B. Journal of Applied Phsiology, 1994, 77, 1890-1895.

[7]. Mc Loughlin, P., Mc Caffery, N. and Moynihan, J.B. European Journal of applied Physiology, 1991 62, 274-278

[8]. Rowell, I., Saltin, B.R., Kiens, B. and Christenson, N.J. Heart Circulation and physiology, 1986, 20 , $038-044$.

[9]. Declan A.J. Connolly, FACSM, Kevin M. Brennan and Christie D. Lauzon. Journal of sport Science and Medicine. 2003, 2, 47 -51.

[10]. Williams C \& Ratel S, eds. Human Muscle Fatigue. Routledge. 2009, 112-114.

[11]. Gill N.D et al. British Journal of Sports Medicine. 2006, 42:260-263.

[12]. Lane KN \& Wenger HA. Journal of Strength and Conditioning Research. 2004, 18:855-860.

[13]. Dupont G, Moalla W, Matran R, Berthoin S. Med Sci Sports Exerc. 2007, Jul; 39(7):1170-6. Seyedhadi Naghibi Annals of Biological Research, 2012, 3 (5):2517-2519 